RECORD COPY

\title{
RESULTS OF FURTHER BETA BACKSCATTER
}

\section{EVALUATION DATA}

\section{(Title Unclassified)}

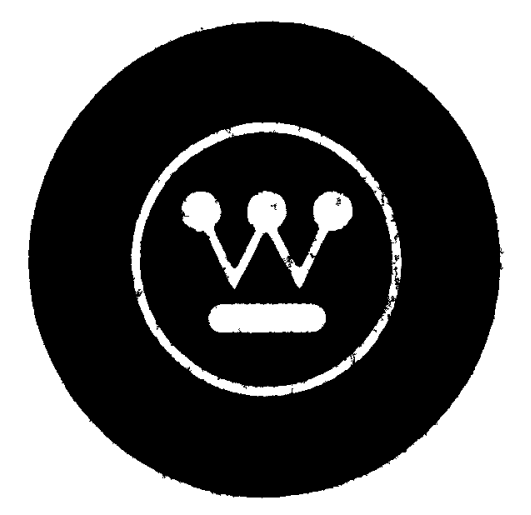




\section{DISCLAIMER}

This report was prepared as an account of work sponsored by an agency of the United States Government. Neither the United States Government nor any agency Thereof, nor any of their employees, makes any warranty, express or implied, or assumes any legal liability or responsibility for the accuracy, completeness, or usefulness of any information, apparatus, product, or process disclosed, or represents that its use would not infringe privately owned rights. Reference herein to any specific commercial product, process, or service by trade name, trademark, manufacturer, or otherwise does not necessarily constitute or imply its endorsement, recommendation, or favoring by the United States Government or any agency thereof. The views and opinions of authors expressed herein do not necessarily state or reflect those of the United States Government or any agency thereof. 


\section{DISCLAIMER}

Portions of this document may be illegible in electronic image products. Images are produced from the best available original document. 
NOTICE -

This report was prepared as an account of work sponsored by the United States Government. Neither the United States nor the United States Energy Research and Development Administration, nor any of their employees, nor any of their contractors, subcontractors, or their employees, makes any warranty, express or implied, or assumes any legal liability or responsibility for the accuracy, completeness or usefulness of any information, apparatus, product or process disclosed, or represents that its use would not infringe privately owned rights.
WANL-TME-1652

August 15, 1967

\section{Westinghouse Astronuclear Laboratory}

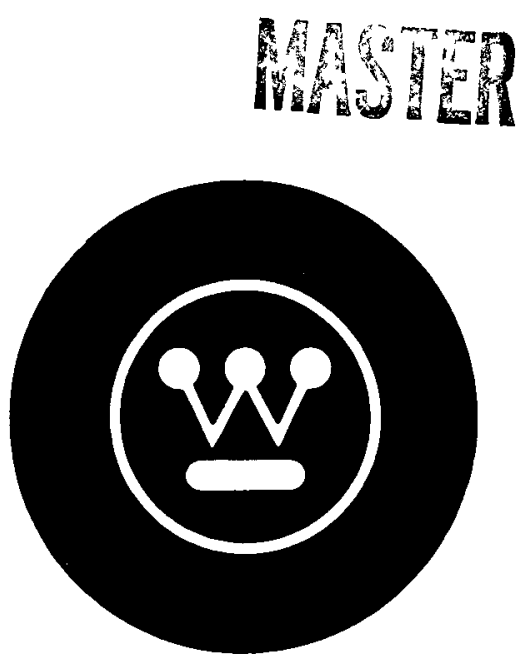

\section{RESULTS OF FURTHER BETA BACKSCATTER}

\section{EVALUATION DATA}

(Title Unclassified)

\begin{tabular}{|c|c|c|}
\hline $\begin{array}{l}\text { SPECIAL I REVINW } \\
\text { FIMLATON } \\
\text { DETERMILATION } \\
\text { Class: U }\end{array}$ & $K A W$ & $\begin{array}{l}\text { Class. } \\
\mathrm{U}\end{array}$ \\
\hline
\end{tabular}

Classification cancelled to

Author:

W. H. Horton

Approved:

Approved:

Wa authority of

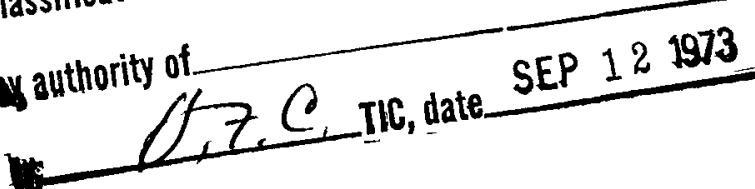

$$
\text { \& Ytugner }
$$

G. L. Wagner

Manager, Reliability

$$
\text { DISTRIBUTION OF THIS DOCUMENT UNLIMITEO }
$$

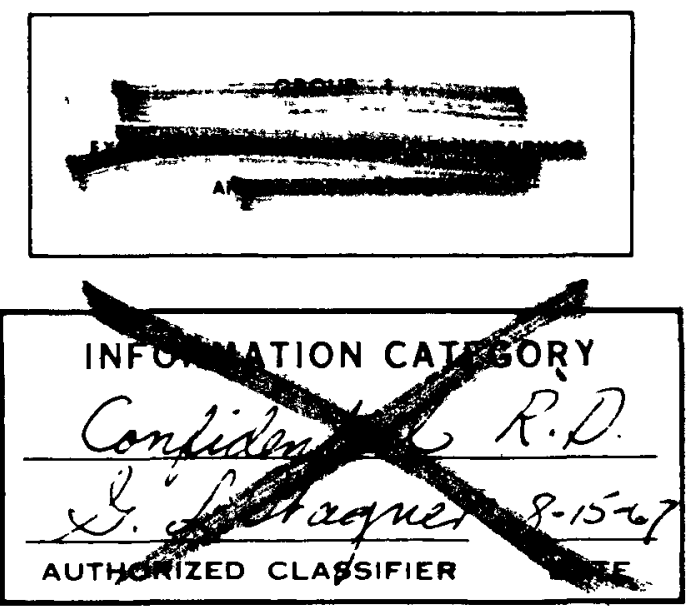

Manager, Product Assurance 


\section{TABLE OF CONTENTS}

Section

1. (CRD) INTRODUCTION

2. (CRD) THE FUNCTIONAL FORM OF THE CALIBRATION CURVE

3. (CRD) EVALUATION OF THE NRX-A6/2 CALIBRATION STANDARDS

4. (CRD) THE CONVERSION OF APPARENT NIOBIUM TO EQUIVALENT NIOBIUM-CARBIDE

5. (CRD) CONCLUSIONS AND RECOMMENDATIONS

\section{LIST OF TABLES}

Table

1. Calibration Data for Evaluation of Functional Form of Calibration Curve

2. Functional Relationships and Corresponding Thicknesses used to Evaluate Calibration Curve Functional Form

3. Standard Errors of Estimate for Three Different Calibration Expressions

4. TME 1244 Evaluation of NRX-A6/2 Calibration Standards

5. NRX-A6/2 Evaluation of Calibrations' Standards

6. Metallographic Niobium-Carbide Data for Four NRX-A6/2 (PAX) Elements

7. Beta Backscatter Equivalent Niobium-Carbide Thicknesses 


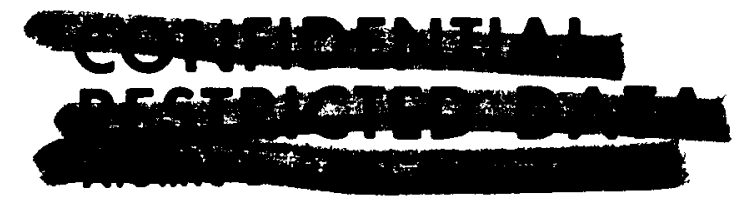

\section{SECTION 1.}

\section{(CRD) INTRODUCTION}

When design requirements for Uranium loadings of fuel elements are released by WANL Engineering, WNCO Quality Engineering immediately initiates fabrication of standards to be used in the calibration of beta backscatter equipment. The steps taken in the fabrication of standards are briefly described as follows:

1) A minimum of two sections from one or more uncoated elements for each loading code are cut;

2) Sheets of Niobium foil of various thicknesses are carefully measured several times;

3) Sections from the Niobium foil sheets having reasonably consistent thicknesses are cut to dimensions comparable to those of a channel in the sectioned elements; and

4) Niobium foil sections are formed into cylinders and inserted into the channels of the sectioned elements.

These steps result in at least two standards for each loading code; each standard generally has six different thicknesses of Niobium foil inserted in six different channels.

Established procedures for evaluating Niobium-Carbide thicknesses in coated elements are such, that these standards must be used to calibrate the beta backscatter equipment response at least once during each shift and more often if various loading codes are involved. The calibration is performed by obtaining three beta backscatter counts for each Niobium foil thickness (including 0.0 thickness, i.e., no foil) for a particular standard (loading code) and introducing these data into a computer program to estimate the coefficients of the calibration curve. As count response data are obtained on coated elements, the appropriate calibration curve is used to convert the count data for these elements to "apparent Niobium" coating thickness. Finally, these Niobium values are converted to "equivalent metallographic Niobium-Carbide" thicknesses by an empirical relationship.

This report presents results obtained in some analyses relative to relationships that could be used to express the calibration curve, the evaluation of beta backscatter standards, and the conversion of apparent Niobium to equivalent Niobium-Carbide. 
As further background, in "Results of Beta Backscatter Data Evaluation", WANLTME-1244, Revision 1, dated August 1965, a functional form for expressing the calibration curve and an empirical relationship for converting to equivalent Niobium-Carbide were recommended. These two expressions were used for evaluating all WNCO coated elements during NRX-A4 and A5 production. TME-1244 also indicated that a discontinuity in the relationship between counts and Niobium foil thickness was seen to occur between foil thickness values of 1.7 and 2.1 mils. For this reason foil thicknesses of 1.7 mils or less were suggested for use in the determination of the calibration curve. Using the empirical conversion formula recommended, an apparent thickness of 1.7 mils would convert to 2.7 mils equivalent Niobium-Carbide, thus, TME-1244 pointed out that some difficulty might be expected if thicknesses greater than 2.7 mils were to be evaluated. As stated earlier, all A4 and A5 WNCO coated elements were evaluated according to the recommended expressions of TME-1244 and with no apparent difficulty.

Beginning with the evaluation of $N R X-A 6 / 1$ coated elements, much thicker NiobiumCarbide values were encountered and erratic beta backscatter thicknesses (as converted) presented a problem. To alleviate this problem, WNCO Quality Engineering changed both the functional form of the calibration curve and the empirical relationship to convert to equivalent Niobium-Carbide. These changes are summarily compared to the expressions recommended in TME-1244 in the following table:

Calibration Curve

TME-1244

$\log (\mathrm{Nb}+1.0)=a+b$ (Counts) using foil thickness of

$0.0,0.5,1.3,1.7$

$N R X-A 6 / 1$ $\log (\mathrm{Nb})=f+g \log$ (Counts)

using foil thicknesses of

$0.5,1.3,1.7,2.1,2.5,3.2$

\section{Conversion Function}

$\mathrm{NbC}=c+d(N b)+e(N b)^{2}$

$\mathrm{NbC}=h+i(\mathrm{Nb})$

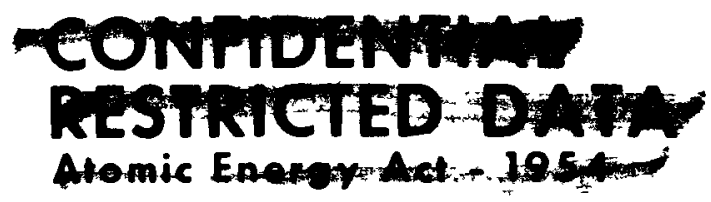


These changes were made from an additional evaluation of the data in TME-1244.

The effectiveness of the changes was more a function of the linearity of the conversion formula than the change in the form of the calibration curve.

NRX-A6/2 design requirements introduced practically a new set of Uranium loadings and subsequently, a need for new beta backscatter standards. At this time, a redesign of the beta backscatter probe to utilize an aluminum encapsulated source rather than the stainless steel encapsulation was also considered. These added conditions, and a desire on the part of WNCO Quality Engineering to make general the conversion of all NDT Niobium-Carbide thickness determinations, led to a further set of changes in the functional form of the calibration curve and the conversion formula.

These changes (new standards, new source design, a different form for the calibration curve, and a different conversion formula) and their effects are evaluated in the following sections.

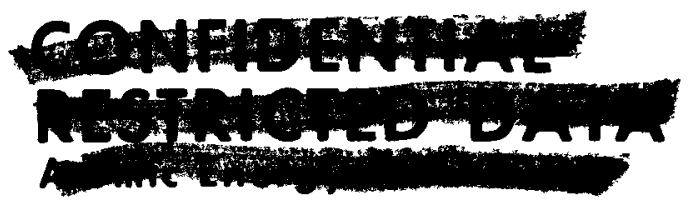


PAGE BLANK 


\section{SECTION 2.}

\section{(CRD) THE FUNCTIONAL FORM OF THE CALIBRATION CURVE}

Table 1 contains data for eleven calibration runs as reported in TME-1244 and data for eight calibration runs obtained during NRX-A6 PAX production; the TME-1244 data reflects the use of stainless steel encapsulated sources and NRX-A4 standards, and the second grouping of data reflects the use of aluminum encapsulated sources and NRX-A6/2 standards. As noted in the table, each set of data consists of three readings for seven Niobium foil thicknesses. These data were processed with a standard "least squares" computer program to evaluate "linear fits" to several functional relationships using all seven or selected Niobium foil thicknesses. (A "linear fit" is a fit to estimate the coefficients in a linear function such as $Y=a+b X$ where $a$ and $b$ are the coefficients.) Table 2 enumerates the functional relationships and corresponding Niobium foil thicknesses evaluated in the "linear fits."

As seen in Table 2, the logarithms of Niobium thickness plus 1.0 (to enable the use of 0.0 thickness), the logarithms of Niobium thickness, and arithmetic Niobium thicknesses were evaluated as functions of counts, logarithms of counts, square roots of counts, reciprocals of counts, and reciprocals of square roots of counts (exception: arithmetic thickness versus counts) using all seven thicknesses, where possible, as well as selected thicknesses for special comparisons. The functional expression, $\log (\mathrm{Nb})=a+b \log$ (Counts), using the last six thickness val ues, was used during $N R X-A 6 / 1$; and the functional expression $\log (N b)=a+b$ $\sqrt{\text { Counts, }}$ using the last six thickness values was scheduled for use during NRX-A6/2. $A$ total of nineteen equations for each of the nineteen sets of calibration data were processed. The purpose of this processing was not to evaluate the coefficients in the linear expressions but to obtain quantities termed, standard errors of estimate, which would indicate the magnitude of the deviations of the observed values from the fitted equations and, in turn, would indicate the "goodness" of the fit.

If, in expressing the calibration curve, a functional form involving log $(\mathrm{Nb}+1.0)$ were used, a standard error of estimate of 0.0050 yields 99 percent confidence limits (when 


\section{TABLE I}

CALIBRATION DATA FOR EVALUATION OF FUNCTIONAL FORM OF CALIBRATION CURVE

(Table Entrles are Bata Backecatter Count Dato)

\begin{tabular}{|c|c|c|c|c|c|c|c|}
\hline $\begin{array}{l}\text { Collibration } \\
\text { Identily }\end{array}$ & \multicolumn{7}{|c|}{ Standard Nrobium Thickness (mils) } \\
\hline \multirow[t]{2}{*}{1 Stainles: } & Encapar & d Soure & ata Ex & ted fro & $E-124$ & & \\
\hline & 00 & 05 & 13 & 17 & 21 & 25 & 32 \\
\hline $3-2$ & $\begin{array}{l}436 \\
435 \\
435\end{array}$ & $\begin{array}{l}584 \\
583 \\
582\end{array}$ & $\begin{array}{l}737 \\
738 \\
735\end{array}$ & $\begin{array}{l}784 \\
788 \\
789\end{array}$ & $\begin{array}{l}827 \\
828 \\
828\end{array}$ & $\begin{array}{l}838 \\
844 \\
839\end{array}$ & $\begin{array}{l}904 \\
904 \\
903\end{array}$ \\
\hline $4-2$ & $\begin{array}{l}46 \\
445 \\
45\end{array}$ & $\begin{array}{l}593 \\
597 \\
593\end{array}$ & $\begin{array}{l}739 \\
742 \\
742\end{array}$ & $\begin{array}{l}796 \\
796 \\
799\end{array}$ & $\begin{array}{l}810 \\
812 \\
810\end{array}$ & $\begin{array}{l}870 \\
869 \\
869\end{array}$ & $\begin{array}{l}896 \\
892 \\
896\end{array}$ \\
\hline $5-1$ & $\begin{array}{l}469 \\
470 \\
472 \\
\end{array}$ & $\begin{array}{l}611 \\
610 \\
610 \\
\end{array}$ & $\begin{array}{l}748 \\
745 \\
750 \\
\end{array}$ & $\begin{array}{r}813 \\
813 \\
814 \\
\end{array}$ & $\begin{array}{l}831 \\
835 \\
835 \\
\end{array}$ & $\begin{array}{l}875 \\
874 \\
874 \\
\end{array}$ & $\begin{array}{l}915 \\
914 \\
913 \\
\end{array}$ \\
\hline $5-2$ & $\begin{array}{l}474 \\
474 \\
473 \\
\end{array}$ & $\begin{array}{l}606 \\
607 \\
611\end{array}$ & $\begin{array}{l}744 \\
744 \\
748\end{array}$ & $\begin{array}{l}809 \\
806 \\
807\end{array}$ & $\begin{array}{l}827 \\
831 \\
831\end{array}$ & $\begin{array}{l}\mathbf{8 5 5} \\
\mathbf{8 5 5} \\
\mathbf{8 5 2} \\
\end{array}$ & $\begin{array}{l}898 \\
900 \\
899\end{array}$ \\
\hline $6-1$ & $\begin{array}{l}482 \\
485 \\
482 \\
\end{array}$ & $\begin{array}{l}617 \\
619 \\
616 \\
\end{array}$ & $\begin{array}{l}744 \\
738 \\
736 \\
\end{array}$ & $\begin{array}{l}801 \\
802 \\
803 \\
\end{array}$ & $\begin{array}{l}831 \\
835 \\
832 \\
\end{array}$ & $\begin{array}{l}871 \\
674 \\
875\end{array}$ & $\begin{array}{l}902 \\
902 \\
904 \\
\end{array}$ \\
\hline $6-2$ & $\begin{array}{l}477 \\
479 \\
477\end{array}$ & $\begin{array}{l}608 \\
612 \\
610\end{array}$ & $\begin{array}{l}747 \\
743 \\
740 \\
\end{array}$ & $\begin{array}{l}817 \\
816 \\
818 \\
\end{array}$ & $\begin{array}{l}828 \\
826 \\
831\end{array}$ & $\begin{array}{l}874 \\
872 \\
870\end{array}$ & $\begin{array}{l}909 \\
909 \\
910\end{array}$ \\
\hline $7-1$ & $\begin{array}{l}510 \\
509 \\
508 \\
\end{array}$ & $\begin{array}{l}641 \\
643 \\
640 \\
\end{array}$ & $\begin{array}{l}770 \\
769 \\
770 \\
\end{array}$ & $\begin{array}{l}821 \\
824 \\
822 \\
\end{array}$ & $\begin{array}{l}866 \\
864 \\
865 \\
\end{array}$ & $\begin{array}{l}879 \\
876 \\
877 \\
\end{array}$ & $\begin{array}{l}905 \\
906 \\
907\end{array}$ \\
\hline $7-2$ & $\begin{array}{l}503 \\
500 \\
505\end{array}$ & $\begin{array}{l}636 \\
635 \\
636\end{array}$ & $\begin{array}{l}772 \\
773 \\
772\end{array}$ & $\begin{array}{l}814 \\
817 \\
818\end{array}$ & $\begin{array}{l}858 \\
858 \\
856\end{array}$ & $\begin{array}{l}864 \\
868 \\
864\end{array}$ & $\begin{array}{l}908 \\
907 \\
906\end{array}$ \\
\hline $8-1$ & $\begin{array}{l}545 \\
546 \\
542 \\
\end{array}$ & $\begin{array}{l}663 \\
668 \\
667\end{array}$ & $\begin{array}{l}792 \\
788 \\
789 \\
\end{array}$ & $\begin{array}{l}838 \\
842 \\
841\end{array}$ & $\begin{array}{l}863 \\
865 \\
859 \\
\end{array}$ & $\begin{array}{l}888 \\
885 \\
886 \\
\end{array}$ & $\begin{array}{l}938 \\
938 \\
942 \\
\end{array}$ \\
\hline $8-2$ & $\begin{array}{l}529 \\
529 \\
527 \\
\end{array}$ & $\begin{array}{l}652 \\
648 \\
649 \\
\end{array}$ & $\begin{array}{l}780 \\
778 \\
778 \\
\end{array}$ & $\begin{array}{l}825 \\
824 \\
820 \\
\end{array}$ & $\begin{array}{l}854 \\
855 \\
849 \\
\end{array}$ & $\begin{array}{l}885 \\
885 \\
885 \\
\end{array}$ & $\begin{array}{l}945 \\
941 \\
942 \\
\end{array}$ \\
\hline 9-AA & $\begin{array}{l}5-15 \\
514 \\
515\end{array}$ & $\begin{array}{l}652 \\
653 \\
650\end{array}$ & $\begin{array}{l}783 \\
782 \\
783\end{array}$ & $\begin{array}{l}831 \\
830 \\
829\end{array}$ & $\begin{array}{l}846 \\
847 \\
845\end{array}$ & $\begin{array}{l}878 \\
879 \\
876\end{array}$ & $\begin{array}{l}927 \\
929 \\
929\end{array}$ \\
\hline \multicolumn{8}{|c|}{2 Standards } \\
\hline & 00 & 055 & 11 & 17 & 20 & 29 & 36 \\
\hline 59012 & $\begin{array}{l}584 \\
584 \\
585 \\
\end{array}$ & $\begin{array}{l}654 \\
655 \\
655 \\
\end{array}$ & $\begin{array}{l}722 \\
722 \\
725 \\
\end{array}$ & $\begin{array}{l}770 \\
773 \\
773 \\
\end{array}$ & $\begin{array}{l}793 \\
795 \\
795 \\
\end{array}$ & $\begin{array}{l}821 \\
823 \\
824 \\
\end{array}$ & $\begin{array}{l}857 \\
858 \\
859 \\
\end{array}$ \\
\hline 59013 & $\begin{array}{l}579 \\
579 \\
579 \\
\end{array}$ & $\begin{array}{l}647 \\
648 \\
650 \\
\end{array}$ & $\begin{array}{l}719 \\
719 \\
721 \\
\end{array}$ & $\begin{array}{l}761 \\
762 \\
765 \\
\end{array}$ & $\begin{array}{l}787 \\
790 \\
791 \\
\end{array}$ & $\begin{array}{l}832 \\
832 \\
834 \\
\end{array}$ & $\begin{array}{l}851 \\
853 \\
854 \\
\end{array}$ \\
\hline 59014 & $\begin{array}{l}585 \\
585 \\
586 \\
\end{array}$ & $\begin{array}{l}657 \\
659 \\
659 \\
\end{array}$ & $\begin{array}{l}726 \\
728 \\
728 \\
\end{array}$ & $\begin{array}{l}775 \\
775 \\
775 \\
\end{array}$ & $\begin{array}{l}794 \\
794 \\
794 \\
\end{array}$ & $\begin{array}{l}826 \\
828 \\
830 \\
\end{array}$ & $\begin{array}{l}854 \\
855 \\
856 \\
\end{array}$ \\
\hline 59015 & $\begin{array}{l}559 \\
561 \\
563 \\
\end{array}$ & $\begin{array}{l}630 \\
632 \\
632 \\
\end{array}$ & $\begin{array}{l}688 \\
689 \\
691 \\
\end{array}$ & $\begin{array}{l}728 \\
729 \\
732 \\
\end{array}$ & $\begin{array}{l}760 \\
761 \\
761 \\
\end{array}$ & $\begin{array}{l}789 \\
791 \\
793 \\
\end{array}$ & $\begin{array}{l}811 \\
812 \\
814 \\
\end{array}$ \\
\hline 59016 & $\begin{array}{l}560 \\
561 \\
561 \\
\end{array}$ & $\begin{array}{l}629 \\
629 \\
631 \\
\end{array}$ & $\begin{array}{l}694 \\
695 \\
695 \\
\end{array}$ & $\begin{array}{l}740 \\
740 \\
741 \\
\end{array}$ & $\begin{array}{l}763 \\
763 \\
767 \\
\end{array}$ & $\begin{array}{l}789 \\
791 \\
792 \\
\end{array}$ & $\begin{array}{l}810 \\
815 \\
816 \\
\end{array}$ \\
\hline 59017 & $\begin{array}{l}561 \\
563 \\
563 \\
\end{array}$ & $\begin{array}{l}630 \\
632 \\
633 \\
\end{array}$ & $\begin{array}{l}694 \\
695 \\
696 \\
\end{array}$ & $\begin{array}{l}726 \\
728 \\
729 \\
\end{array}$ & $\begin{array}{l}759 \\
760 \\
762 \\
\end{array}$ & $\begin{array}{l}793 \\
795 \\
796 \\
\end{array}$ & $\begin{array}{l}809 \\
814 \\
816 \\
\end{array}$ \\
\hline 59018 & $\begin{array}{l}554 \\
555 \\
555 \\
\end{array}$ & $\begin{array}{l}630 \\
630 \\
631 \\
\end{array}$ & $\begin{array}{l}689 \\
690 \\
693 \\
\end{array}$ & $\begin{array}{l}725 \\
726 \\
727 \\
\end{array}$ & $\begin{array}{l}750 \\
751 \\
752 \\
\end{array}$ & $\begin{array}{l}789 \\
789 \\
794 \\
\end{array}$ & $\begin{array}{l}807 \\
808 \\
810 \\
\end{array}$ \\
\hline 59019 & $\begin{array}{r}550 \\
552 \\
552 \\
\end{array}$ & $\begin{array}{r}627 \\
628 \\
628 \\
\end{array}$ & $\begin{array}{l}689 \\
692 \\
692 \\
\end{array}$ & $\begin{array}{l}731 \\
731 \\
732 \\
\end{array}$ & $\begin{array}{l}756 \\
758 \\
758 \\
\end{array}$ & $\begin{array}{l}790 \\
796 \\
797 \\
\end{array}$ & $\begin{array}{l}812 \\
814 \\
817 \\
\end{array}$ \\
\hline
\end{tabular}




\section{TABLE 2}

FUNCTIONAL RELATIONSHIPS AND CORRESPONDING THICKNESSES

USED TO EVALUATE CALIBRATION CURVE FUNCTIONAL FORM

\begin{tabular}{|c|c|c|c|}
\hline & (Data & Used Is As Given & \\
\hline$\underline{Y}$ & $a+b$ & $\underline{x}$ & Nb Thicknesses Used \\
\hline $\log (\mathrm{Nb}+1.0)$ & & Counts & First 4, Last 6, All 7 \\
\hline $\log (\mathrm{Nb}+1.0)$ & & Log Counts & All 7 \\
\hline $\log (N b+1.0)$ & & $\sqrt{\text { Counts }}$ & All 7 \\
\hline $\log (\mathrm{Nb}+1.0)$ & & $1 /$ Counts & All 7 \\
\hline $\log (\mathrm{Nb}+1.0)$ & & $1 / \sqrt{\text { Counts }}$ & All 7 \\
\hline $\log (\mathrm{Nb})$ & & Counts & Last 6 \\
\hline $\log (\mathrm{Nb})$ & & Log Counts & Last 6, 2-5 \\
\hline $\log (\mathrm{Nb})$ & & $\sqrt{\text { Counts }}$ & Last 6, 2-5 \\
\hline $\log (\mathrm{Nb})$ & & $1 /$ Counts & Last 6 \\
\hline $\log (\mathrm{Nb})$ & & $1 / \sqrt{\text { Counts }}$ & Last 6 \\
\hline $\mathrm{Nb}$ & & Log Counts & First 4, All 7 \\
\hline $\mathrm{Nb}$ & & $\sqrt{\text { Counts }}$ & All 7 \\
\hline $\mathrm{Nb}$ & & $1 /$ Counts & All 7 \\
\hline $\mathrm{Nb}$ & & $1 / \sqrt{\text { Counts }}$ & All 7 \\
\hline
\end{tabular}




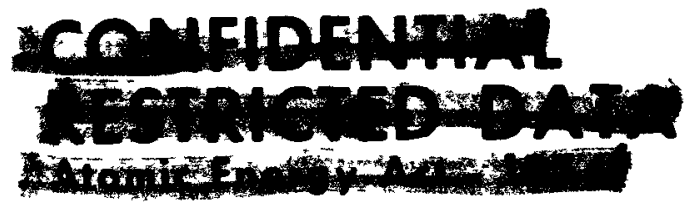

converted to arithmetic thickness) of $0.94-1.06$ at 1.0 mils and $1.91-2.09$ at 2.0 mils. Similarly, a standard error of estimate of 0.0100 yields 99 percent confidence limits of $0.88-1.12$ at 1.0 mils and $1.83-2.19$ at 2.0 mils. In contrast, if a functional form involving $\log (\mathrm{Nb})$ were used, standard errors of estimate of 0.0100 and 0.0180 yield 99 percent confidence limits of $0.94-1.06$ and $0.90-1.11$ at 1.0 mils and $1.88-2.12$ and $1.80-2.23$ at 2.0 mils respectively. Thus, to be equivalent, functional expressions involving $\log (\mathrm{Nb}+1.0)$ must attain standard errors of estimate at least one-half of those for functional forms involving $\log (\mathrm{Nb})$. This implies that the maximum standard errors of estimate for calibration curves expressed in terms of $\log (\mathrm{Nb}+1.0)$ and $\log (\mathrm{Nb})$ should be less than 0.0100 and 0.0180 respectively.

In examining the standard errors of estimate for the functional relationships given in Table 2, applying the maximum tolerable value as implied in the previous paragraph, only three expressions should be considered. These are:

1) $\log (\mathrm{Nb})+1.0=a+b$ Counts, using the first 4 thicknesses;

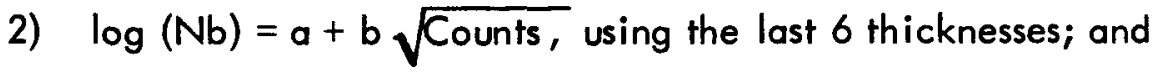

3) $\log (\mathrm{Nb})=a+b \log$ (Counts), using the last 6 thicknesses.

Of the last four expressions given in Table 2 and considering $\mathrm{Nb}$ as some function of counts, the expression, $\mathrm{Nb}=a+b \log$ (Counts), for which the first 4 thicknesses were used, was by far the best; this was undersirable because of the rather large standard errors of estimate.

Table 3 tabulates the standard errors of estimate as derived from the "least squares" fits of the three expressions given in the previous paragraphs to the calibration data of Table 1. Readily observed in this table are the significantly lower values for the TME- 1244 data as treated by the expression recommended in the same TME (equation 1. of the table). The standard errors for the aluminum source data indicate that the differences between the three equations as seen for the TME-1244 data are not as clearly defined.

TME-1244 stated that the variability in counts for repeated determinations during a calibration run is approximately \pm 4 counts independent of the thickness being measured. If 
TABLE 3

\section{STANDARD ERRORS OF ESTIMATE FOR THREE DIFFERENT CALIBRATION EXPRESSIONS}

(Using Calibration Data from Table 1)

1. Stainless Steel Encapsulated Source Data Excerpted from TME-1244)

\begin{tabular}{|c|c|c|c|}
\hline $\begin{array}{l}\text { Calibration } \\
\text { Identity }\end{array}$ & $\begin{array}{l}\text { Equation* } \\
1 . \\
\end{array}$ & $\begin{array}{l}\text { Equation* } \\
2 .\end{array}$ & $\begin{array}{l}\text { Equation* } \\
3 .\end{array}$ \\
\hline $3-2$ & 0.0040 & 0.0163 & 0.0181 \\
\hline $4-2$ & 0.0036 & 0.0243 & 0.0247 \\
\hline $5-1$ & 0.0059 & 0.0185 & 0.0182 \\
\hline $5-2$ & 0.0050 & 0.0180 & 0.0206 \\
\hline $6-1$ & 0.0083 & 0.0248 & 0.0218 \\
\hline $6-2$ & 0.0105 & 0.0262 & 0.0259 \\
\hline $7-1$ & 0.0037 & 0.0248 & 0.0267 \\
\hline $7-2$ & 0.0048 & 0.0189 & 0.0225 \\
\hline $8-1$ & 0.0036 & 0.0186 & 0.0163 \\
\hline $8-2$ & 0.0032 & 0.0214 & 0.0148 \\
\hline 9-AA & 0.0053 & 0.0180 & 0.0173 \\
\hline
\end{tabular}

2. Aluminum Encapsulated Source Data (Data taken on NRX-A6/2 Standards)

\begin{tabular}{|c|c|c|c|}
\hline Identity & $\begin{array}{c}\text { Equation* } \\
1 . \\
\end{array}$ & $\begin{array}{l}\text { Equation* } \\
2 . \\
\end{array}$ & $\begin{array}{l}\text { Equation* } \\
3 . \\
\end{array}$ \\
\hline 59012 & 0.0131 & 0.0176 & 0.0182 \\
\hline 59013 & 0.0144 & 0.0137 & 0.0135 \\
\hline 59014 & 0.0155 & 0.0093 & 0.0128 \\
\hline 59015 & 0.0073 & 0.0230 & 0.0224 \\
\hline 59016 & 0.0115 & 0.0193 & 0.0222 \\
\hline 59017 & 0.0129 & 0.0246 & 0.0239 \\
\hline 59018 & 0.0093 & 0.0189 & 0.0169 \\
\hline 59019 & 0.0077 & 0.0157 & 0.0153 \\
\hline
\end{tabular}

*Equation 1. $\log (\mathrm{Nb}+1.0)=a+b$ Counts, using first 4 thicknesses

2. $\log (N b)=a+b \sqrt{\text { Counts, }}$ using last 6 thicknesses

3. $\log (\mathrm{Nb})=a+b \log ($ Counts), using last 6 thicknesses 
it is assumed that this consistency in counts from thickness to thickness implies that the calibration curve should reflect a linear function of counts, then the increase in the standard errors of estimate for the aluminum source data when evaluated by equation 1. of Table 3 indicates that a) there has been a possible deterioration in the equipment response, b) the aluminum encapsulated sources are more sensitive to extraneous effects, or $c$ ) that the NRX-A6/2 standards are not as well fabricated as those for NRX-A4. Of these three possibilities, the possible deterioration in equipment response is discounted by examination of the three readings per Niobium thickness as given in the calibration data of Table 1. Aluminum encapsulated sources are expected to be at least as good in their performance as the stainless steel sources: thus, the remaining possibility for the increase in variability is the NRX-A6/2 standards. Data and analyses presented in the following section will indicate that there are some poor standards and that the variability (as expressed by the standard errors of estimate) has not increased if proper standards were selected. 


\section{SECTION 3}

\section{(CRD) EVALUATION OF NRX-A6/2 CALIBRATION STANDARDS}

The closing paragraphs of the previous section indicated the possibility of some low quality NRX-A6/2 calibration standards and a means for assessing their quality by evaluating the standard errors of estimate associated with the calibration curves. Low quality standards actually are quite probable whenever the uncertainty of the gauging of the Niobium foil thickness and the insertion of the proper dimension (circumferential) in the channel of the sectioned element is considered. Tie these two uncertainties into the urgency created by the rather late release of NRX-A6/2 fuel element loadings and the probability increases even more. Nevertheless, NRX-A6/2 required new standards and these were hurried in their fabrication.

As stated earlier, standards generally have seven thicknesses $(0.0 \mathrm{mi} / \mathrm{s}$ plus six thicknesses of Niobium foil). Some foil sheet stock still remained from NRX-A4 standards fabrication and was used in the fabrication of the new standards; however, the thickness values assigned to this foil were changed. One change was that of 0.5 to 0.55 mils; possibly this change was associated with the increased variability noted for the aluminum source data of Tables 1 and 3. Subsequent to the analyses summarized in Table 3, another foil thickness was changed. These changes are indicated in the following table:

\begin{tabular}{clc}
$\begin{array}{c}\text { NRX-A4 Standards } \\
\text { Nb Foil Thicknesses (mils) }\end{array}$ & $\begin{array}{r}\text { NRX-A6/2 Sta } \\
\text { Nb Foil Thickness }\end{array}$ \\
\cline { 3 - 3 } 0.0 & became & 0.0 \\
0.5 & different sheet stock & 0.55 \\
1.3 & became & 1.1 \\
1.7 & became & 1.6 \\
2.1 & different sheet stock & 2.0 \\
2.5 & different sheet stock & 2.9 \\
3.2 & 3.6
\end{tabular}


Since the calibration expression recommended in TME-1244 would use only the first four thicknesses ( 0.0 plus the first three foil thicknesses), the changes of 0.5 to $0.55 \mathrm{mils}$ and 1.7 to 1.6 mils would be expected to affect the standard errors of estimate for the calibration curves. Similarly, these changes would also affect the standard errors if the expression log $(\mathrm{Nb})$ versus $\sqrt{\text { Counts }}$ were used for the last six thicknesses, though not as much and in a different direction.

Twelve sets of four standards each had been fabricated for $N R X-A 6 / 2$, and calibration data had been obtained on all 48 standards within a two day period. To evaluate these standards, their calibration data were processed by the "least squares" program to consider $\log (\mathrm{Nb}+1.0)$ and $\log (\mathrm{Nb})$ as linear functions of either Counts or $\sqrt{\text { Counts }}$ (the com-

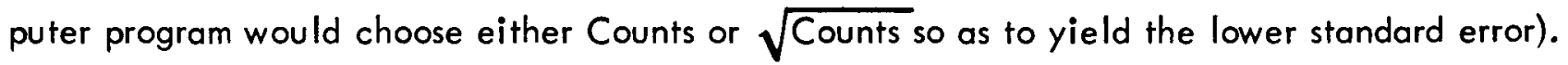
Using the first four thicknesses, four equations were evaluated for $\log (\mathrm{Nb}+1.0)$, each equation generated by considering the four combinations of 0.5 or 0.55 mils and 1.7 or 1.6 mils coupled with 0.0 and 1.1 mils. Similarly, using the last six thicknesses, four equations were evaluated for $\log (\mathrm{Nb})$. Using thicknesses values of $0.0,0.5,1.1$, and 1.7 mils, the equation expressing $\log (\mathrm{Nb}+1.0)$ as a function of Counts, if the computer chose Counts, it would be similar to that recommended in TME-1244. Using thickness values of $0.55,1.1$, $1.6,2.0,2.9$, and 3.6 mils, the equation expressing $\log (\mathrm{Nb})$ as a function of $\sqrt{\text { Counts, }}$

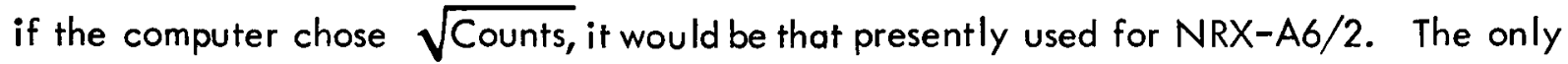
information of interest in the examination of all the fitted expressions (a total of 384) was the apparent changes in the intercepts, slopes, and standard errors of estimate as the different thickness values were interchanged. Such changes would naturally be expected, but these can contribute little to the evaluation of the standards.

Information that does contribute significantly to the selection of high quality standards is given in Tables 4 and 5. Table 4 summarizes the evaluation of the standards as though the TME-1244 calibration curve were to be used. Using as a selection guide a maximum standard error of estimate of $0.0100,34$ of the 48 standards evaluated should give acceptable calibration data with 5 additional standards having standard errors slightly above 0.0100. Also seen in this table is a decrease in the intercept plus an increase in the slope as loading increases.

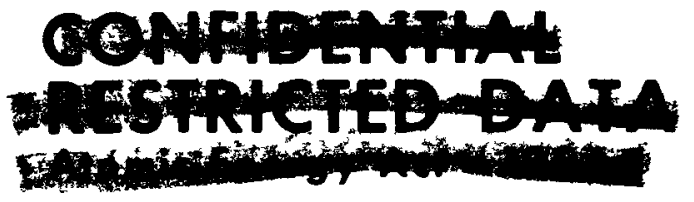



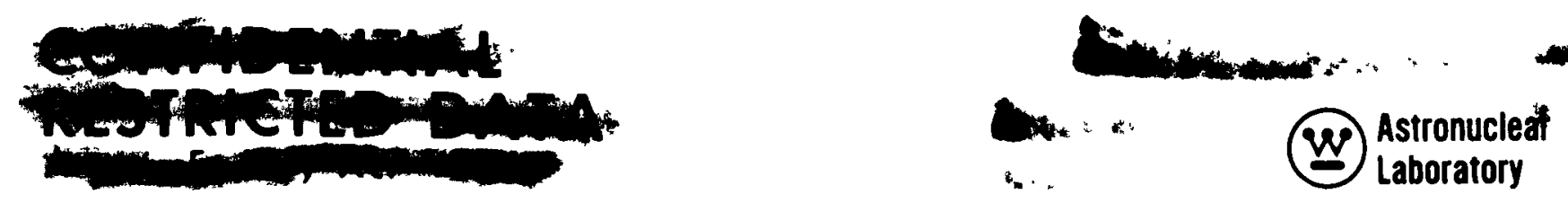

TABLE 4

\section{TME - 1244 EVALUATION OF NRX-A6/2 CALIBRATION STANDARDS}

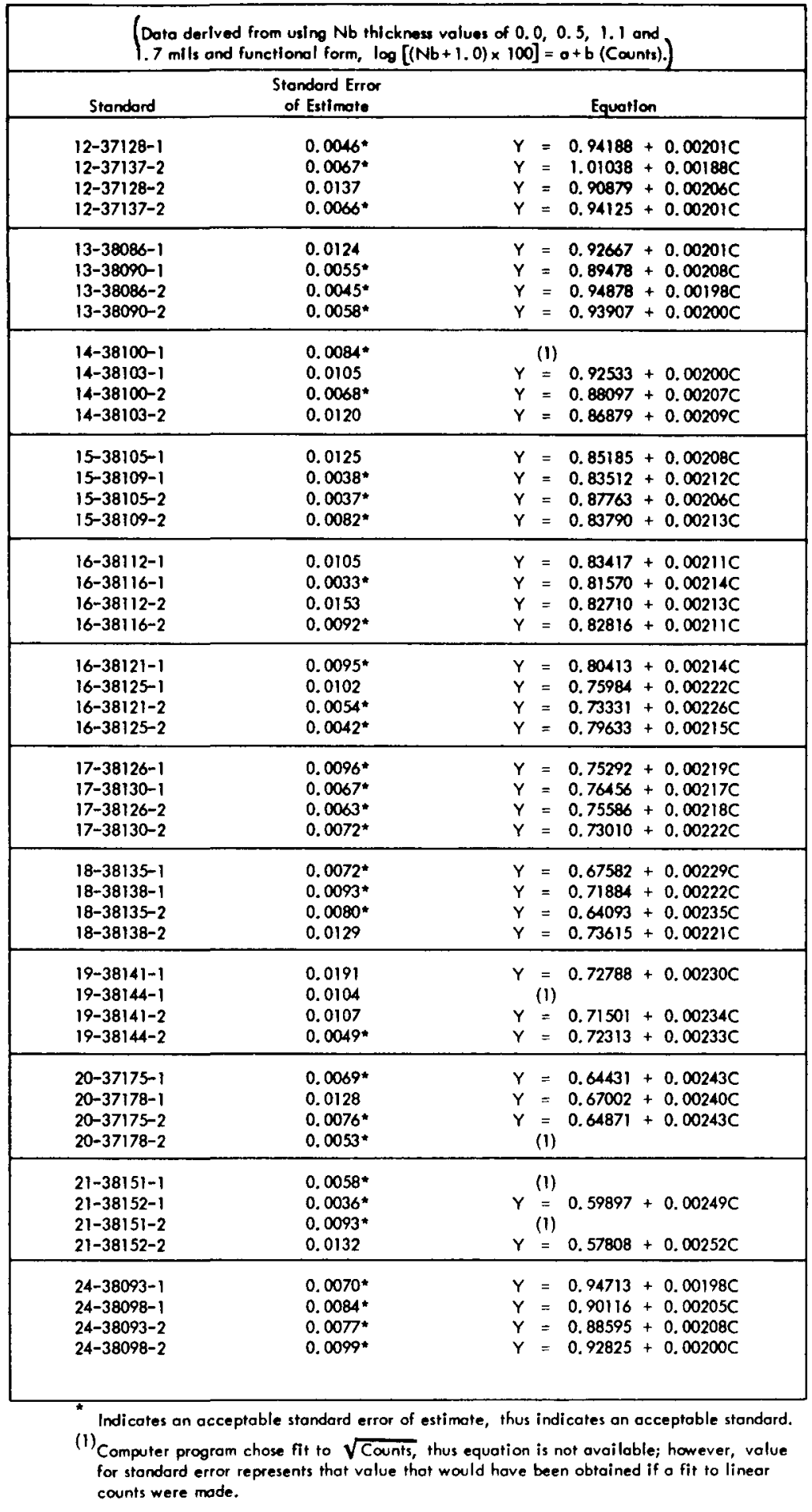

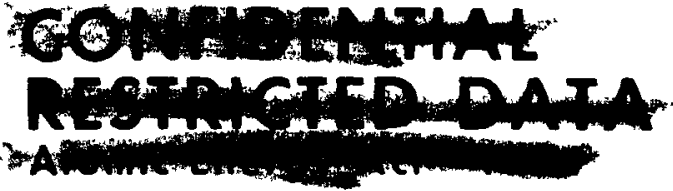




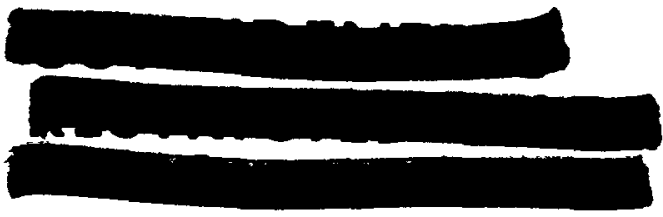

TABLE 5

\section{NRX-A6/2 EVALUATION OF CALIBRATION STANDARDS}

(Data derived from using Nb thickness values of $0.55,1.1,1.6,2.0,2.9$

and $3.6 \mathrm{mils}$ and functional form, $\log (100 \mathrm{Nb})=a+b \sqrt{\text { Counts. }})$

\begin{tabular}{|c|c|c|}
\hline Standard & $\begin{array}{c}\text { Standard Error } \\
\text { Of Estimote }\end{array}$ & Equation \\
\hline $\begin{array}{l}12-37128-1 \\
12-37137-1 \\
12-37128-2 \\
12-37137-2 \\
\end{array}$ & $\begin{array}{l}0.0113^{\star} \\
0.0161^{\star} \\
0.0195 \\
0.0066^{\star}\end{array}$ & $\begin{array}{l}Y=-2.89700+0.18784 \sqrt{C} \\
(1) \\
Y=-2.96677+0.19026 \sqrt{C} \\
Y=-2.85728+0.18619 \sqrt{C}\end{array}$ \\
\hline $\begin{array}{l}13-38086-1 \\
13-38090-1 \\
13-38086-2 \\
13-38090-2 \\
\end{array}$ & $\begin{array}{l}0.0111^{\star} \\
0.0211 \\
0.0146^{\star} \\
0.0076^{\star}\end{array}$ & $\begin{array}{l}Y=-3.07497+0.19332 \sqrt{C} \\
Y=-2.89559+0.18725 \sqrt{C} \\
(1) \\
Y=-2.90947+0.18761 \sqrt{C}\end{array}$ \\
\hline $\begin{array}{l}14-38100-1 \\
14-38103-1 \\
14-38100-2 \\
14-38103-2\end{array}$ & $\begin{array}{l}0.0164^{\star} \\
0.0145^{\star} \\
0.0126^{\star} \\
0.0186\end{array}$ & $\begin{array}{l}(1) \\
(1) \\
Y=-3.24990+0.19989 \sqrt{C} \\
Y=-3.09310+0.19348 \sqrt{C}\end{array}$ \\
\hline $\begin{array}{l}15-38105-1 \\
15-38109-1 \\
15-38105-2 \\
15-38109-2\end{array}$ & $\begin{array}{l}0.0116^{\star} \\
0.0104^{\star} \\
0.0102^{\star} \\
0.0095^{\star}\end{array}$ & $\begin{array}{l}Y=-3.51167+0.20802 \sqrt{C} \\
Y=-3.30401+0.20104 \sqrt{C} \\
Y=-3.32903+0.20236 \sqrt{C} \\
Y=-3.32017+0.20200 \sqrt{C}\end{array}$ \\
\hline $\begin{array}{l}16-38112-1 \\
16-38116-1 \\
16-38112-2 \\
16-38116-2 \\
\end{array}$ & $\begin{array}{l}0.0110^{\star} \\
0.0127^{\star} \\
0.0166^{\star} \\
0.0092^{\star}\end{array}$ & $\begin{array}{l}Y=-3.43699+0.20533 \sqrt{C} \\
Y=-3.39110+0.20422 \sqrt{C} \\
Y=-3.26203+0.19943 \sqrt{C} \\
Y=-3.38739+0.20334 \sqrt{C}\end{array}$ \\
\hline $\begin{array}{l}16-38121-1 \\
16-38125-1 \\
16-38121-2 \\
16-38125-2\end{array}$ & $\begin{array}{l}0.0091^{\star} \\
0.0152^{\star} \\
0.0260 \\
0.0118^{\star}\end{array}$ & $\begin{array}{l}Y=-3.45381+0.20532 \sqrt{\frac{C}{C}} \\
Y=-3.41416+0.20469 \sqrt{\frac{C}{C}} \\
Y=-3.38118+0.20312 \sqrt{C} \\
Y=-3.51503+0.20799 \sqrt{C}\end{array}$ \\
\hline $\begin{array}{l}17-38126-1 \\
17-38130-1 \\
17-38126-2 \\
17-38130-2\end{array}$ & $\begin{array}{l}0.0220 \\
0.0106^{*} \\
0.0106^{*} \\
0.0146^{\star}\end{array}$ & $\begin{array}{l}(1) \\
Y=-3.60322+0.20971 \sqrt{C} \\
\text { (1) } \\
\text { (1) }\end{array}$ \\
\hline $\begin{array}{l}18-38135-1 \\
18-38138-1 \\
18-38135-2 \\
18-38138-2 \\
\end{array}$ & $\begin{array}{l}0.0129^{*} \\
0.0083^{*} \\
0.0169^{*} \\
0.0084^{*}\end{array}$ & $\begin{array}{l}Y=-3.94141+0.22236 \sqrt{C} \\
Y=-3.85293+0.21831 \sqrt{C} \\
Y=-3.89903+0.22095 \sqrt{C} \\
Y=-3.88665+0.22028 \sqrt{C}\end{array}$ \\
\hline $\begin{array}{l}19-38141-1 \\
19-38144-1 \\
19-38141-2 \\
19-38144-2 \\
\end{array}$ & $\begin{array}{l}0.1111 \\
0.0217 \\
0.0084^{\star} \\
0.0143^{\star}\end{array}$ & $\begin{array}{l}Y=-3.03389+0.19203 \sqrt{C} \\
\text { (1) } \\
\text { (1) } \\
\text { (1) }\end{array}$ \\
\hline $\begin{array}{l}20-37175-1 \\
20-37178-1 \\
20-37175-2 \\
20-37178-2 \\
\end{array}$ & $\begin{array}{l}0.0131^{*} \\
0.0128 * \\
0.0121 * \\
0.0189\end{array}$ & $\begin{array}{l}Y=-4.11465+0.23352 \sqrt{C} \\
Y=-3.90688+0.22586 \sqrt{C} \\
Y=-4.04387+0.23097 \sqrt{C} \\
(1)\end{array}$ \\
\hline $\begin{array}{l}21-38151-1 \\
21-38152-1 \\
21-38151-2 \\
21-38152-2\end{array}$ & $\begin{array}{l}0.0204 \\
0.0192 \\
0.0157^{\star} \\
0.0192\end{array}$ & $\begin{array}{l}\text { (1) } \\
Y=-4.19132+0.23610 \sqrt{C} \\
(1) \\
\text { (1) }\end{array}$ \\
\hline $\begin{array}{l}24-38093-1 \\
24-38098-1 \\
24-38093-2 \\
24-38098-2\end{array}$ & $\begin{array}{l}0.0100^{\star} \\
0.0097^{\star} \\
0.0155^{\star} \\
0.0095^{\star}\end{array}$ & $\begin{array}{l}(1) \\
Y=-3.10039+0.19426 \sqrt{C} \\
Y=-2.97598+0.19001 \sqrt{C} \\
(1)\end{array}$ \\
\hline
\end{tabular}

* Indicates an acceptable standard error estimate, thus indicates an acceptable standard (1) Computer progrom chose fit to linear counts, thus equ ation is not available; however, value for standand error represents that value that would have been obtained if a fit to $\sqrt{\text { Counts were made. }}$

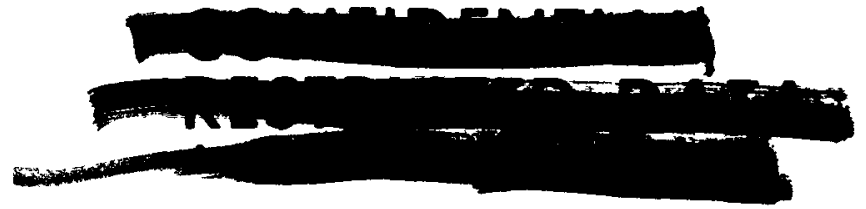



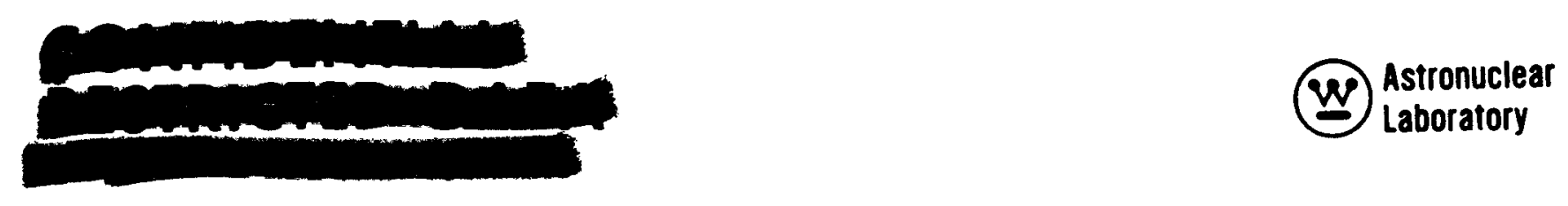

Table 5 summarizes the evaluation of the standards for the functional form presently being used for $N R X-A 6 / 2$ production. Using as a selection guide a maximum standard error of estimate of $0.0180,37$ of the 48 standards evaluated should give acceptable calibration data with 2 additional standards having standard errors slightly above 0.0180 . In this table it is noted that the intercept decreases and the slope increases as loading increases.

The data in Table 4 also indicates that the equipment response from the aluminum encapsulated sources is comparable to that discussed in TME-1244 and as derived from the stainless steel sources. As for a direct comparison between using the functional form of TME1244 and that form presently being used, none can be made due to the use of different thickness values for the calibration data. Using their own particular thicknesses, each leads to calibration curves equally as effective, in so far as expected deviations from the fitted curve are concerned; however, this is not to say that both result in the same apparent Niobium thicknesses. Each will require its own empirical conversion formula to return data readily comparable to metallographic Niobium-Carbide thickness. 
PAGE BLANK 


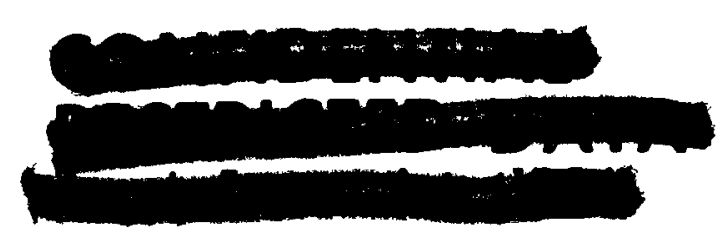

\section{(20) Astronuclear}

\section{SECTION 4}

\section{(CRD) THE CONVERSION OF APPARENT NIOBIUM TO EQUIVALENT NIOBIUM-CARBIDE}

To convert apparent Niobium thickness as derived from beta backscatter response to equivalent Niobium-Carbide thickness as derived from metallographic examination, WANLTME-1244 recommended an empirical relationship obtained from an analysis of the data given in that report. This relationship expressed Niobium-Carbide thickness as a quadratic function of apparent Niobium thickness and was used for all of the NRX-A4 and A5 production. With the introduction of NRX-A6/1, production and thicker Niobium-Carbide coatings, difficulty with respect to their evaluation was encountered. WNCO Quality Engineering re-evaluated the data of TME-1244 and adopted as the expression for calibration the functional form log thickness versus log counts and as the conversion function, an expression relating NiobiumCarbide as a linear function of apparent Niobium.

TME-1244, in one of its recommendations, stated that the expression for conversion is an empirical one and that periodic checks should be made of the agreement that the relationship implies. From the difficulty experienced in NRX-A6/1 production, it is apparent that the implied agreement of the TME-1244 relationship was no longer the rule, probably because of thicker coatings.

NRX-A6/2 production, introduced new Uranium loadings and the need for new calibration standards. During this period, a redesign of the beta backscatter probe to consider aluminum encapsulated sources became desirable. These two factors led WNCO Quality Engineering to re-evaluate both the calibration and conversion expressions. As given earlier, calibration curves expressing log Niobium thickness as a function of the square root of Counts were adopted. This particular functional form was chosen consistent with Quality Engineering's desire to make general the conversion of all NDT Niobium-Carbide thickness determinations. As for the conversion of apparent Niobium to equivalent Niobium-Carbide, the following expressions are to be used for NRX-A6/2 production:

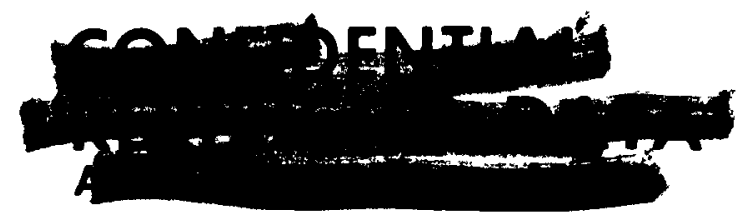




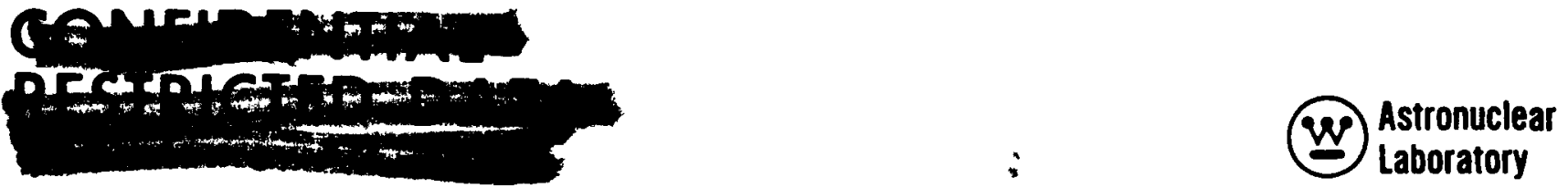

TABLE 6 METALLOGRAPHIC NIOBIUM-CARBIDE DATA FOR FOUR
NRX-A6/2 (PAX) ELEMENTS

(Table entries are metallographic Niobium-Carbide thicknesses in mils)

Position

$\frac{21-38922}{\text { Channel }} \quad \frac{19-38855}{\text { Channel }} \quad \frac{14-62611}{\text { Channel }} \quad \frac{11-62165}{\text { Channel }}$

From $S / \mathbb{N}$
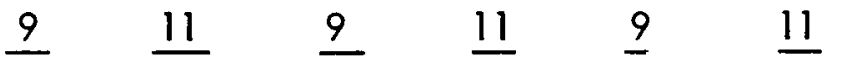

$\underline{9}$

11

4.5

0.78

0.81

0.86

0.82

0.76

0.79

0.94

0.95

7.5

0.88

0.91

0.92

0.88

0.86

0.85

0.99

1.00

10.5

0.94

0.91

0.93

0.92

0.90

$1.07 \quad 1.10$

13.5

1.04

0.98

$1.09 \quad 1.04$

1.01

1.00

$1.26 \quad 1.25$

16.5

1.12

1.10

1.13

1.13

1.10

1.11

1.34

1.26

$1.17 \quad 1.20$

1.09

1.04

1.09

1.19

1.40

1.42

22.5

25.5

28.5

31.5

1.24
1.14

1.20

$1.18 \quad 1.26$

1.17

$1.24 \quad 1.25$

1.33

1.22

$\begin{array}{ll}1.28 & 1.27\end{array}$

1.30

1.16

1.25

1.27

1.29

1.58

1.50

$1.34 \quad 1.36$

1.36

1.34

1.32

1.34

1.63

1.66

34.5

1.40

1.42

1.42

1.41

1.32

1.36

1.84

1.89

37.5

1.48

1.51

1.54

1.44

1.50

1.54

2.08

2.14

1.55

1.47

1.58

1.51

1.57

$\begin{array}{ll}1.52 & 1.52\end{array}$

1.61

1.57

2.18

2.21

$1.51 \quad 1.59$

$1.63 \quad 1.65$

1.64

1.57

2.44

2.48

46.5

$1.66 \quad 1.62$

1.83

1.81

$\begin{array}{ll}1.68 & 1.66\end{array}$

2.42

2.55

$1.71 \quad 1.66$

2.76

2.83

49.5

3.08

2.93

3.16 
Using the same calibration and element count data, these data were also processed by the calibration technique recommended in TME-1244. Thus, the calibration curve form used was that expressing $\log (\mathrm{Nb}+1.0)$ as a function of counts; for the calibration curves, Niobium thicknesses of $0.0,0.5$ (not 0.55 ), 1.1 and 1.7 (not 1.6) mils were assumed. From the calibration curves, beta backscatter count data for the four elements were processed to yield apparent Niobium thicknesses values. Finally, these apparent Niobium values were processed with the metallographic data of Table 6 to obtain an empirical relationship for conversion of apparent Niobium to equivalent Niobium-Carbide.

In obtaining the empirical relationship, two expressions were derived. The first of these was derived from a use of all the data and is

$$
\mathrm{NbC}=-0.045+1.420 \mathrm{Nb}
$$

the second is

$$
\mathrm{NbC}=-0.053+1.427 \mathrm{Nb}
$$

and was derived excluding the data for the code 11 element having the much thicker NiobiumCarbide coating. As is evident, there is little difference in these two expressions. Thus, the second expression, intended for a range of thickness from 0.8 to 1.8 mils, could be used to cover effectively a thickness range of 0.8 to $3.1 \mathrm{mils}$.

Beta backscatter count data for the four elements were converted to equivalent Niobium-Carbide thicknesses by the two approaches discussed in this section. These equivalent Niobium-Carbide thicknesses are given in Table 7 and may be directly compared to the metallographic data of Table 6. The agreement between metallography and beta backscatter, using either approach, is essentially the same and as expressed by 99 percent confidence limits would be approximately $\pm 0.17 \mathrm{mils}$ over the range of thicknesses from 0.8 to $1.8 \mathrm{mils}$ and approximately \pm 0.21 over the range of thicknesses from 1.8 to 3.1 mils.

A comparison of the equivalent thicknesses as determined by the two approaches (see Table 7) will reveal that the TME-1244 approach will yield higher thickness values from 0.8 to 1.5 mils, lower values from 1.5 to $2.5 \mathrm{mils}$, and higher values from 2.5 to $3.2 \mathrm{mils}$. These

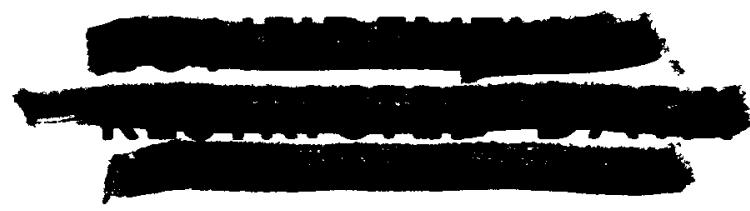




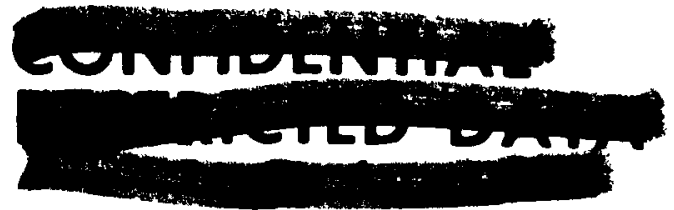

(w) Astronuclear

TABLE 7

BETA BACKSCATTER EQUIVALENT NIOBIUM-CARBIDE THICKNESSES

(Table entries are equivalent beta backscatter Niobium-Carbide thicknesses in mils.)

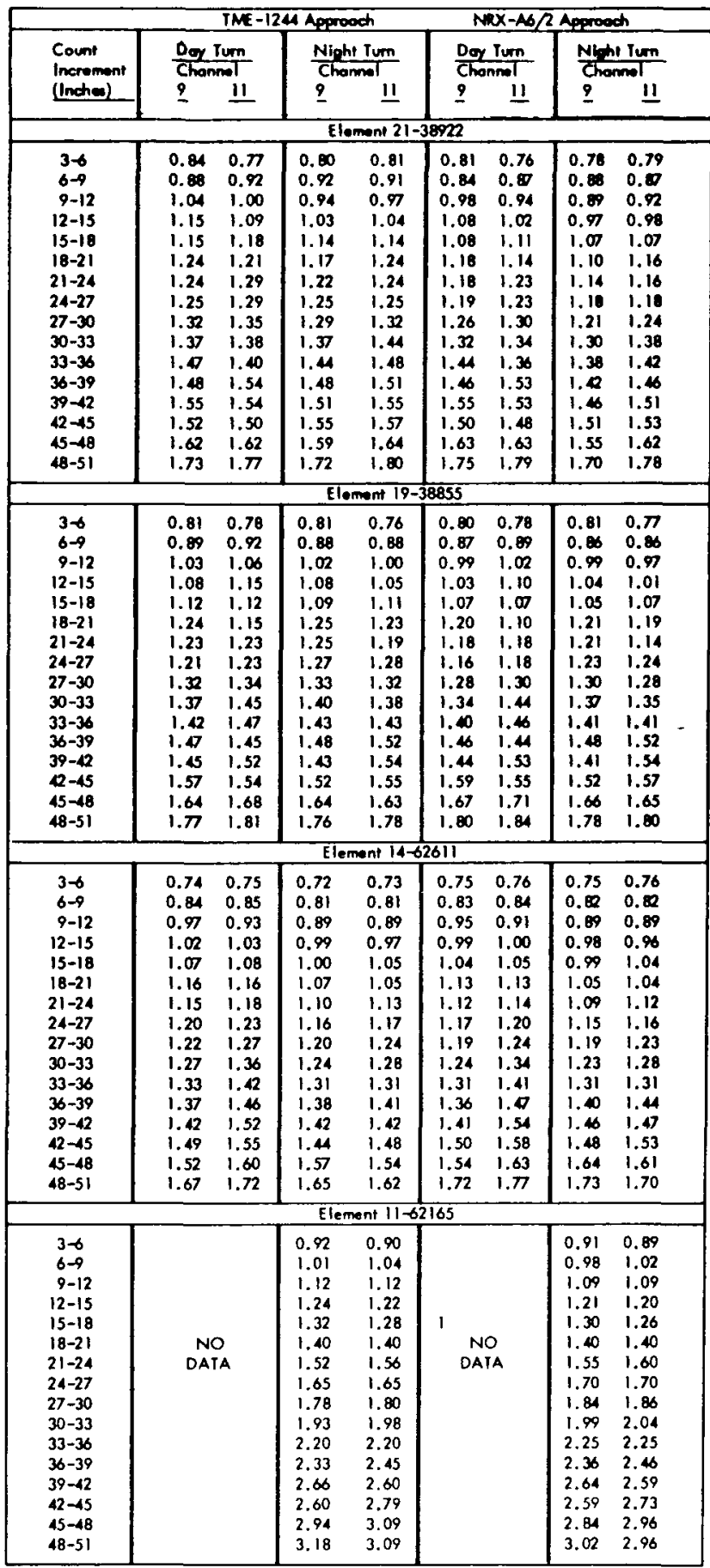




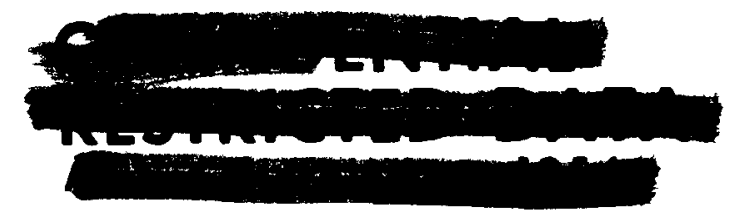

(w) Astronuclear

differences, though comparatively small, are a reflection of the three expressions for conversion as used in the NRX-A6/2 approach versus the single expression used in the TME-1244 approach. Actually, equivalent thickness values from one approach will be lower (higher) than the other over approximately the first half, and higher (lower) than the other over the remaining part of the range of thicknesses covered by each of the three expressions of the NRX-A6/2 approach. 


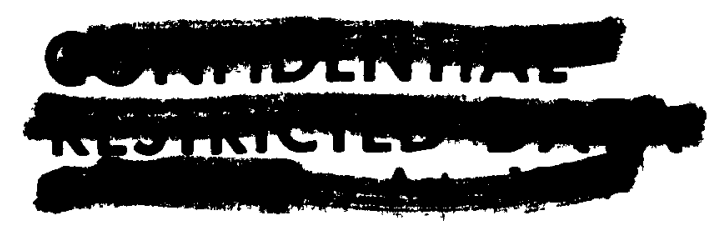

(W) Astronuclear

\section{SECTION 5}

\section{(CRD) CONCLUSIONS AND RECOMMENDATIONS}

With the beginning of the NRX-A6/2 production of fuel elements, WNCO introduced four general changes in the evaluation of Niobium-Carbide thickness by beta backscatter. The changes were:

1) A redesign of the beta backscatter probe to consider an aluminum encapsulated source rather than the stainless steel encapsulation,

2) A new set of beta backscatter standards, due to changes in Uranium loadings,

3) A different functional form for the calibration curve, and

4) A set of expressions for use in converting apparent Niobium per beta backscatter to equivalent Niobium-Carbide as obtained metallographically.

All data analyzed, for the preparation of this report, lead to the conclusion that probes with aluminum encapsulated sources have responses equally as effective as those with stainless steel encapsulation. Count data taken with the new probes for calibration vary within the \pm 4 units reported in WANL-TME-1244 as that expected for the three measurements obtained for each standard Niobium foil thickness and is independent of the thickness being measured. Since the probe redesign was primarily to attain longer probe life, the new probes should be continued in service.

In evaluating the functional form of the calibration curve, the first set of data appeared to indicate that calibration data deviated significantly--more than could be expected from the information reported in TME-1244. This can be attributed to two different events; 1) the use of improper Niobium foil thickness values in the calibration formulation, and 2) the inadvertent use of some poorer quality calibration standards. In the latter case, all NRX-A6/2 calibration standards were new, with meager experience in their use. To prevent any further difficulty relative to the inadvertent use of poorer quality standards, all were evaluated and the results of this evaluation summarized in Tables 4 and 5.

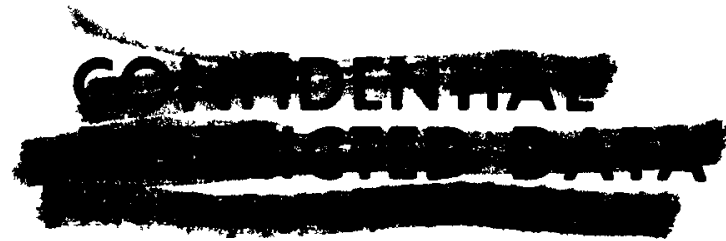




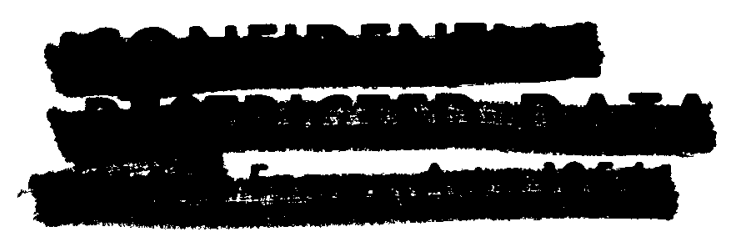

(2) Astronuclear Laboratory

Referring to these tables, those standards not indicated as acceptable should be discarded; of those that are acceptable, those standards having the smallest standard errors of estimate within each loading code should be used as the primary calibration standards.

Also to be noted in Table 4 or 5 is the large number of standards that have been made. This number is a function of the number of different fuel loadings and the requirements for calibration. Since each standard uses foil difficult to measure and is difficult to make, in future applications, consideration should be given to reducing the number of standards needed while, at the same time, improving the overall quality of the set. A possible way of reducing the number required may rest in a method using a limited number of loadings wherein loading effects may be inferred. With fewer standards, greater care with respect to the quality of each should prove to be beneficial.

Again referring to Tables 4 and 5, the evaluation of standards was based upon what should be considered as the maximum limit tolerable for a standard error of estimate for a calibration curve. If the functional form of the calibration curve considers the fit of $\log (\mathrm{Nb}+$ 1.0) as a function of Counts, then the maximum limit would be 0.0100 . On the other hand, if the functional form considers the fit of $\log (\mathrm{Nb})$, then the maximum limit would be 0.0180. Not only can limits such as these be used to evaluate the acceptability of new standards but these should be used to evaluate the acceptance of each and every calibration curve.

TME-1244 considered the functional form of the calibration curve to be that of $\log (\mathrm{Nb}+1.0)$ as a linear function of Counts, whereas the functional form presently being used is that of $\log (\mathrm{Nb})$ as a linear function of the square root of Counts. In expressing the calibration curve in terms of $\log (\mathrm{Nb}+1.0)$, the 0.0 mils thickness plus any foil thicknesses less than $1.8 \mathrm{mils}$ (generally 3 different thicknesses) would be used. If the calibration curve is expressed in terms of $\log (\mathrm{Nb})$, the 0.0 mils thickness is ignored but all foil thicknesses (generally 6 different thicknesses with the maximum less than 4.0 mils) would be used. From the data covered in this report, these two functional forms were found to be essentially equivalent but only if certain foil thicknesses (different for each expression) were assumed. It should be apparent from the previous statement that the functional form of the calibration curve has

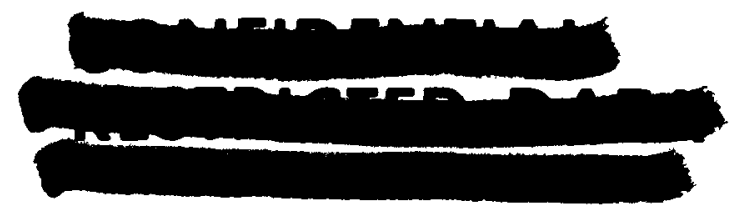


not been explicitly determined. This will be accomplished only if Niobium foil thicknesses used in the calibration standards are better defined and controlled more rigorously in their placement in the standards.

From metallographic examination of four NRX-A6/2 (PAX) elements, NiobiumCarbide thicknesses were used to establish relationships for converting apparent Niobium thickness from beta backscatter to equivalent Niobium-Carbide. A single linear expression, $\mathrm{NbC}=-0.053+1.427 \mathrm{Nb}$, using the TME-1244 calibration approach was found to be sufficient over the range of Niobium-Carbide thicknesses observed. WNCO, using the same data and the NRX-A6/2 calibration approach, derived three expressions. These also were found to be sufficient to cover the range of thicknesses observed with differences in equivalent Niobium-Carbide thicknesses as computed from either approach negligible.

Since the conversion expressions are empirical as well as semi-dependent upon the calibration form, these should be reviewed every 3 to 6 months to ensure their effectiveness. At the present time, either of the two approaches and their data as discussed herein could be used. 